\title{
Factors related to dry mouth and low salivary flow rates in diabetic elderly: a systematic literature review
}

\author{
Fatores relacionados a boca seca e hipossalivação em idosos diabéticos: uma revisão
}

\section{Abstract}

This study aimed to perform a systematic review of studies on factors related to xerostomia and/or hyposalivation in elderly patients with diabetes. SciELO, Science Direct, Scopus, and PubMed/Medline databases were searched for articles published from January 1992 to January 2013, concerned with factors associated with/related to xerostomia or hyposalivation in elderly patients with diabetes. Five articles were selected, including four transversal studies and one longitudinal study. Some of the studies found relationship between poor glycemic control and hyposalivation. Others found that xerostomia was more frequent in patients who worked in nondomestic environments and in women. However, there was considerable variation in the methods used by the researchers in the selected studies. We could not draw definitive conclusions based on our analysis of the selected studies. Longitudinal studies with appropriate sample sizes are needed to provide more complete information about the factors related to xerostomia and hyposalivation in elderly patients with diabetes.

\section{Resumo}

O objetivo deste estudo foi realizar uma revisão sistemática de estudos existentes sobre os fatores relacionados à xerostomia e/ou à hipossalivação em idosos diabéticos. Busca sistemática foi realizada nas bases de dados SciELO, Science Direct, Scopus e PubMed/ Medline entre janeiro de 1992 e janeiro de 2013, coletando artigos cujo objetivo tenha sido encontrar fatores associados/relacionados à xerostomia e/ou à hipossalivação em idosos diabéticos. Cinco artigos foram selecionados, sendo quatro estudos transversais e um longitudinal. Alguns trabalhos encontraram relação entre o mau controle glicêmico e o surgimento de hipossalivação. Outros encontraram que a xerostomia foi mais frequente em pacientes que trabalhavam em ambientes não domésticos e em mulheres. Entretanto, os aspectos metodológicos utilizados pelos pesquisadores variaram bastante entre os trabalhos selecionados. Conclusões definitivas não puderam ser retiradas com base na análise dos trabalhos selecionados. Estudos longitudinais com adequado tamanho da amostra são necessários para fornecer informações mais adequadas quanto aos fatores relacionados xerostomia e hipossalivação em idosos diabéticos.

\footnotetext{
Curso de Odontologia. Universidade Potiguar (Laureate International Universities). Natal, RN, Brasil

2 Departamento de Odontologia, Centro de Ciências da Saúde. Universidade Federal do Rio Grande do Norte. Natal, RN, Brasil.
}

Everton Freitas de Morais'

Rômulo Augusto de Paiva Macedo' Jadson Alexandre da Silva Lira'

Kenio Costa de Lima² Boniek Castillo Dutra Borges ${ }^{2}$

Key words: Xerostomia. Elderly. Diabetes Mellitus. Saliva.

Palavras-chave: Xerostomia. Idoso. Diabetes Mellitus. Saliva. 


\section{INTRODUCTION}

The increased proportion of older adults in the world population and the corresponding increased rates of chronic diseases, such as type 2 diabetes mellitus (DM), are important concerns for doctors and public health policy-makers. ${ }^{1} \mathrm{DM}$ is a metabolic disease that affects around 285 million people, or $6.4 \%$ of the world population. ${ }^{2}$ Stomatological changes, including xerostomia (dry-mouth sensation) and hyposalivation (reduction in salivary secretion) are common among patients with DM. ${ }^{3,4}$ There are various reports of an association between diabetes and xerostomia and hyposalivation. Doctors have detected high rates of hyposalivation and xerostomia in elderly patients with DM. ${ }^{5}$

Salivary secretions are important to oral health, assisting in mechanical cleaning and serving protective functions through physiological and biochemical mechanisms. Hyposalivation contributes to the development of various health problems that can have serious negative effects on the quality of life of the patient, affecting their eating habits, nutritional state, palate, speech, and tolerance of dental prostheses. Such effects may increase the risk of oral infection, including candidiasis, and the patient's susceptibility to dental caries, periodontal disease, and tooth loss. ${ }^{6}$ Xerostomia is responsible for a series of oral changes with several symptoms, such as burning mouth syndrome, palatal changes, aspiration, altered sensitivity, and difficulty in chewing, deglutination, and speech. ${ }^{7}$

Although previous studies have evaluated the factors that are related to the appearance of xerostomia and hyposalivation in elderly patients with $\mathrm{DM},{ }^{8-12}$ there is a need for systematic analysis of these results. This study aimed to perform a systematic literature review to identify which factors are related to the presence of xerostomia and/or hyposalivation in elderly patients with DM.

\section{MATERIALS AND METHODS}

PubMed/Medline, SciELO, Science Direct, and Scopus databases were systematically searched for studies published between January 1992 and January 2013 that evaluated the factors associated with/related to the presence of xerostomia and/or hyposalivation in elderly patients with DM. Table 1 shows the search strategies applied.

This systematic review conducted a search using the following keywords: "elderly", "hyposalivation", "xerostomia", "diabetes" and its synonyms in the English language. The possible databases used Boolean operators AND, OR, NOT. Figure 1 shows the sequence of steps used for bibliographic search.

After the abstracts were obtained, three evaluators independently analyzed, evaluated all full-papers, and selected the relevant studies according to the following inclusion and exclusion criteria. Inclusion criteria were: study published in English; original data arising from scientific research; studies whose objective was to evaluate factors associated with/related to the presence of xerostomia and/or hyposalivation in elderly patients with DM. Exclusion criteria were: review studies; studies on animals.

Studies were firstly selected by analyzing the titles/abstracts, and then analyzing the complete articles. Articles were included in the data system after the evaluators formed a consensus about them. 
Table 1. Search strategies and number of papers found in each database. Natal-RN, Brazil, 2013.

\begin{tabular}{llccc}
\hline \multicolumn{1}{c}{ Search strategy } & A & B & C & D \\
\hline $\begin{array}{l}\text { (Elderly OR older OR aged) AND (xerostomia OR "dry mouth" } \\
\begin{array}{l}\text { OR "oral dryness" OR "impaired salivary flow") AND (diabetes } \\
\text { OR diabetic). }\end{array}\end{array}$ & 0 & 2456 & 10 & 216 \\
\hline $\begin{array}{l}\text { (Elderly OR older OR aged) AND (hyposalivation OR "salivary } \\
\text { hypofunction" OR "reduced salivary flow" OR "low salivary } \\
\text { flow" OR "decrease salivary flow") AND (diabetes OR diabetic). }\end{array}$ & 0 & 3047 & 17 & 177 \\
\hline
\end{tabular}

$\mathrm{A}=$ SciELO; $\mathrm{B}=$ Science Direct $\mathrm{C}=$ Scopus $\mathrm{D}=$ PubMed $/$ Medline.
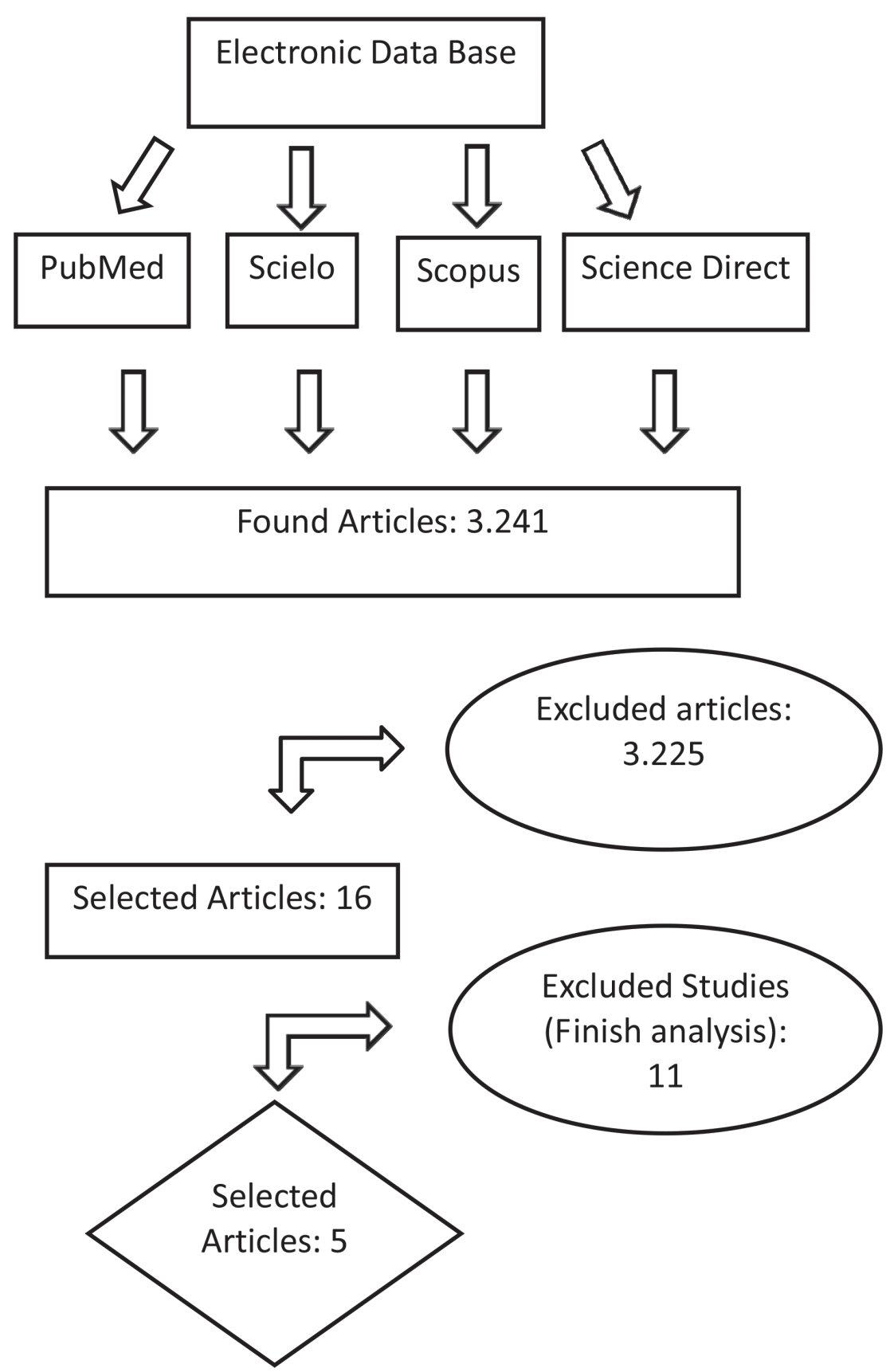

Figure 1. Flowchart of the completion of the systematic review. 


\section{RESULTS}

Of the 3,241 articles found in different databases, 16 had the potential to be included in this study based on the abstracts. Only five studies met the inclusion criteria of the study, while other studies had design flaws or did met any exclusion criterion. We categorized the content of the articles, as shown in table 2. Four studies had a cross-sectional design, ${ }^{8,9,11,12}$ whereas only one study had a longitudinal design. ${ }^{10}$ Three studies occurred in developed countries, ${ }^{9,10,12}$ and two in developing countries. ${ }^{8,11}$ Three studies used a comparison group. ${ }^{9-11}$ The sample size ranged from 39 to 150 , totaling 395 people. The study population consisted of men and women with DM. The selected studies were of nonrandomized type, and all valuated the sensation of xerostomia; three studies measured saliva flow in patients. ${ }^{8-10}$ All studies used a questionnaire for patients to measure the subjective sensation of oral safety.

The three studies that evaluated saliva flow measured stimulated saliva by the spitting method $^{8-10}$ and non-stimulated saliva by paraffin ${ }^{8}$ or $2 \%$ citric acid. ${ }^{11,12}$ The rate of saliva produced by each person was determined by the ratio between the saliva volume and the duration of the collection period $(\mathrm{ml} / \mathrm{min}){ }^{8-10}$ Borges et al. ${ }^{8}$ defined hyposalivation as non-stimulated flow rate $<0.1 \mathrm{ml} / \mathrm{min}$ and simulated flow rate $<0.7 \mathrm{ml} /$ min. ${ }^{8}$ Chávez et al. ${ }^{9,10}$ classified hyposalivation as low or normal non-stimulated saliva flow according to population standards $(\leq 0.2 \mathrm{ml} / \mathrm{min}$ for men and $\leq 0.18 \mathrm{ml} / \mathrm{min}$ for women). These studies did not indicate how they analyzed the stimulated flow.

Among the variables analyzed were socioeconomic factors, ${ }^{8-10}$ medical conditions and patient health, ${ }^{9-11}$ disease control, ${ }^{10-12}$ presence of peripheral neuropathy, ${ }^{12}$ use of medications, ${ }^{8-10,12}$ sex, ${ }^{10-12}$ and age. ${ }^{10-12}$ Some studies compared patients with DM to a comparison group. ${ }^{9-11}$ Results showed a relationship $(\mathrm{p}<0.05)$ between xerostomia and elderly people who worked outside the home ${ }^{8}$ and women. ${ }^{11}$ Hyposalivation showed association with glycemic control of the disease ${ }^{9,10}$ and the use of one or more xerostomic medications. ${ }^{9,10}$ Table 2 shows the methods used to measure saliva flow and xerostomia, and the results obtained by each article selected. 


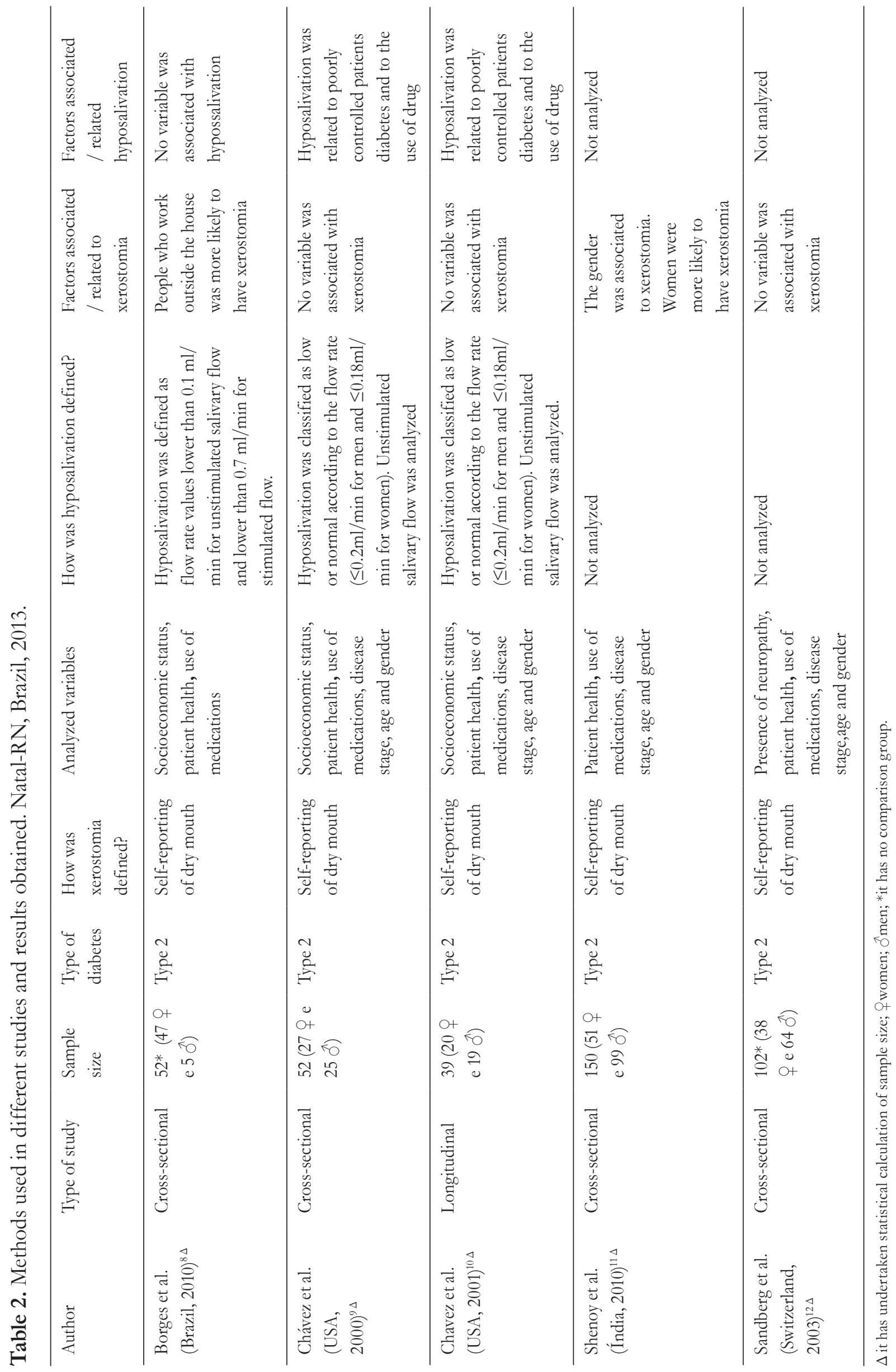




\section{DISCUSSION}

Five out of the 16 initially selected studies were included in the final systematic review and analysis. Of the studies analyzed, the largest sample involved 150 people, whereas the smallest had 39 subjects (mean \pm SD, $79 \pm 46.4$ patients; median, 52 patients). All five studies analyzed factors that might be related to xerostomia in elderly patients with DM..$^{8-12}$ Three studies analyzed factors that might be related to hyposalivation. ${ }^{8-10}$

In terms of the differences in the proportion of men to women in the samples, two studies had predominantly male subjects. ${ }^{11,12}$ The studies by Chávez et al. ${ }^{9,10}$ had equal numbers of men and women. Only one study investigated had more women involved in the research. Shenoy et al. ${ }^{11}$ observed a higher rate of xerostomia in women, but found no factor related to this result, which may have occurred because of differences in the socio-economic factors of the individuals.

The studies by Chávez et al., ${ }^{910}$ did not find a relationship between sex and hyposalivation or xerostomia. Moreover, those studies analyzed the relationship between the presence of poorly controlled DM, a variable that was not analyzed by Borges et al. ${ }^{10}$ or Shenoy et al..$^{11}$ Chávez et al. ${ }^{9,10}$ concluded that xerostomia is independent of the control of DM.

The article by Sandberg et al. ${ }^{12}$ was the only study to evaluate the relationship between xerostomia and the presence of peripheral neuropathy, but the association did not yield significant results. Borges et al. ${ }^{8}$ and Chávez et al. ${ }^{9,10}$ found no relationship between medication use and xerostomia. Borges et $a .^{8}$ related xerostomia to elderly patients who worked outside the home, which, according to the authors, meant that they had less access to water than other people. Chávez et al. ${ }^{9,10}$ did not find a statistical relationship between the prevalence of xerostomia and patients of a more advanced age or with the length of time that they had their disease.

The studies by Chávez et al. ${ }^{9,10}$ related hyposalivation to poor control of DM and to the use of xerostomic medication. The authors listed the medications used by the patients and classified the drugs based on reference guides ${ }^{13,14}$ and web searches. Among the medications that contributed to dry mouth,there were antihypertensive, antidepressant, anxiolytic, anticholinergic, and antihistamine drugs, and specific procedures, such as radiation therapy to treat cancer. ${ }^{15}$

Additionally, Chávez et al., ${ }^{910}$ correlated hyposalivation on the stimulated saliva exam $(\mathrm{p}=0.04)$, but they did not find significant correlation with non-stimulated saliva. According to the authors, the fact that people with poorly controlled DM tended to have less stimulus to their salivary glands may have caused this result. These studies also found that the lack of correlation between xerostomia and hyposalivation in patients with DM may have been be related to factors such as low glycemic control. Other factors - such as depression, anxiety, and stress - may also be related to the final results of the study. Borges et al. ${ }^{8}$ did not detect variables related to hyposalivation, although this study did not evaluate the elderly patients' control of their DM.

The longitudinal analysis by Chávez et al. ${ }^{10}$ found relationship between medication and hyposalivation at the start $(\mathrm{p}=0.0005)$ and end $(p=0.03)$ of the study. This same study also demonstrated that people with poor control of DM were more likely to have hyposalivation. Chávez et al. ${ }^{9,10}$ found a relationship between the medication use and hyposalivation. However, Borges et al. ${ }^{8}$ did not find a relationship between the use of medication and hyposalivation.

Several aspects of the methods adopted by the different studies might have caused limitations that could have affected the accuracy and validity of the inferred estimates. The most common limitations were: the use of few samples, short tracking periods, not calculating the sample size, the lack of a comparison group, and the inclusion of only patients with type $2 \mathrm{DM}$ in all studies. Therefore, longitudinal studies with larger sample sizes, comparison groups, and use of 
different variables that might affect saliva flow in elderly patients with DM are needed to obtain deeper knowledge of and greater clarity about this subject.

\section{CONCLUSION}

The results of this analysis, with evidence published between January 1992 and January 2013, indicate that we cannot draw definitive conclusions about the factors that cause xerostomia and/or hyposalivation in elderly patients with DM. The studies need to be replicated, with a closer examination of the variables that might influence or confuse the results, such as sex, age, type of diabetes, duration of the disease, level of metabolic control, use of medications, presence of peripheral neuropathy, socioeconomic and psychological factors, and state of the patient's overall and oral health. Longitudinal studies with appropriate sample sizes and comparison groups are needed to provide more conclusive results.

\section{REFERENCES}

1. Abbatecola AM, Maggi S, Paolisso G. New approaches to treating type 2 diabetes mellitus in the elderly: role of incretin therapies. Drugs Aging 2008;25(11):913-25.

2. International Diabetes Federation. IDF Diabetes Atlas. 4 ed. Brussels: IFD; 2009.

3. Carda C, Carranza M, Arriaga A, Diaz A, Peydró A, Ferraris MEG. Structural differences between alcoholic and diabetic parotid sialosis. Med Oral Patol Oral Cir Bucal 2005;10(4):309-14.

4. Narhi TO, Meurman JH, Ainamo A. Xerostomia and hyposalivation: Causes, consequences and treatment in the elderly. Drugs Aging 1999;15(2):103-16.

5. Mata AD, Marques D, Rocha S, Francisco H, Santos C, Mesquita MF, et al. Effects of diabetes mellitus on salivary secretion and its composition in the human. Mol Cell Biochem 2004;261(1-2):137-42.

6. Atkinson JC, Wu AJ. Salivary gland dysfunction: causes, symptoms, treatment. J Am Dent Assoc 1994;125(4):409-16.

7. Turner MD, Ship JA. Dry mouth and its effects on the oral health of elderly people. J Am Dent Assoc 2007;138 Supl:15S-20S.

8. Borges BCD, Fulco GM, Souza AJC, De Lima KC. Xerostomia and hyposalivation: a preliminary report of their prevalence and associated factors in Brazilian elderly diabetic patients. Oral Health Prev Dent 2010;8(2):153-8.

9. Chávez EM, Taylor GW, Borrell LN, Ship JÁ. Salivary function and glycemic control in older persons with diabetes. Oral Surg Oral Med Oral Pathol Oral Radiol Endod 2000;89(3):305-11.

10. Chávez EM, Taylor GW, Borrell LN, Ship JA. A longitudinal analysis of salivary flow in control subjects and older adults with type 2 diabetes. Oral Surg Oral Med Oral Pathol Oral Radiol Endod 2001;91(2):166-73.

11. Shenoy N, Sholapurkar AA, Pai KM, Adhikari P. Oral health status in geriatric diabetics. Rev Clín Pesq Odontol 2010;6(1):63-9.

12. Sandberg GE, Wikblad, KF. Oral dryness and peripheral neuropathy in subjects with type 2 diabetes. J Diabet Complicat 2003;17(4):192-8.

13. Lacy C, Armstrong LL, Ingrim NB, Lance LL. Drug Information Handbook. 6th ed. Hudson: Lexi-Comp; 1998.

14. Sreebny LM, Schwartz SS. A Reference Guide to Drugs and Dry Mouth. 2nd ed. Gerodontology 1997;14(1):33-47

15. Lamey PJ, Murray BM, Eddie SA, Freeman RE. The secretion of parotid saliva as stimulated by $10 \%$ citric acid is not related to precipitating factors in burning mouth syndrome. J Oral Pathol Med 2001;30(2):121-4. 